Liver transplantation has now come of age: it gives a chance of excellent rehabilitation for patients with no other treatment available, and the operation is probably less costly than prolonged care of a patient dying of liver disease in hospital. 1 Starzl TE, Koep LJ, Halgrimson CG, et al. Fifteen years of clinical liver
transplantation. Gastroenterology $1979 ; 77: 375-88$.

2 Penn I, Makowski EL, Harris P. Parenthood following renal and hepatic transplantation. Transplantation 1980;30:397-400.

3 Advisory Committee to the Renal Transplant Registry. The 13th report of the Human Renal Transplant Registry. Transplant Proc 1977;IX:9-26.

- Fortner JG, Kinne DW, Shiu MH, et al. Clinical liver heterotopic (auxiliary) transplantation. Surgery 1973;74:739-51.

5 Houssin D, Franco D, Berthelot P, Bismuth H. Heterotopic liver transplantation in end-stage HBsAg-positive cirrhosis. Lancet 1980;i: 990-2,3.

\section{Bilateral amblyopia and race}

The quiet drift of population from the Caribbean to a few urban centres in Britain became for a short time in the 1950s a rushing tide. One of the consequences of this movement was the increased frequency with which otherwise healthy members of this ethnic group were found to suffer from bilateral amblyopia. Needless to say, these cases at first presented formidable diagnostic problems and many were investigated in depthwithout, however, the discovery of any consistent abnormality.

By 1962 sufficient experience had been gained to recognise the essential features of this syndrome. ${ }^{1}$ These features were a relatively rapid onset of bilateral failure of vision giving rise to reading difficulty, the affected individual usually being young and otherwise fit; varying degrees of central and peripheral perimetric defects; and pallor of the optic disc. The ophthalmic state was otherwise unremarkable. The clinical historysometimes difficult to obtain-suggested an initial rapid deterioration of vision in both eyes simultaneously terminating in an enduring non-progressive phase. Most patients were seen at this stage, and subsequent examinations provided some confirmation that the arrested phase had been established. Apparently rapid fluctuations of vision, however, might also be encountered owing to the unreliability of tests of visual acuity in the presence of severe visual deficit, especially when associated with central scotomatous defects. The natural history is thus characterised by a relatively short "active" phase terminating in an "arrested" phase.

The clinical interest aroused by these Caribbean cases led to the discovery that an identical syndrome occurred in Africans living in London who originated from West Africa-the parent country of the West Indian population of African descent.

A further series of patients, both West Indian and West African, presenting with this condition has been reported recently and, like several other reviews published since 1962, it shows the same pattern of clinical manifestations and supports the view that there is no recognisable causative factor. ${ }^{2}$ In the latest series visual-evoked responses had been measured during the stationary period. The records showed subnormal amplitude and delay of the peak of the major positive wave. In one patient repeated visual-evoked responses showed increasing latency despite the absence of any change in visual acuity. This suggests that the loss of function is primarily in the neural elements and is associated with transsynaptic degeneration of nerve fibres-a common phenomenon in the eye.

The cause of the disease is most likely to be genetic (with or without some environmental trigger), even though familial cases form only a minute proportion. A mode of inheritance that would explain this lack of a familial pattern has been suggested by $\mathrm{J} \mathrm{H}$ Renwick, with two independently inherited variant genes. ${ }^{2}$

The wide variation in the prevalence of specific HLA antigens in different ethnic groups is now well recognised. Theoretically therefore the "active" phase of this disorder could be explained by "molecular mimicry" between certain histocompatibility antigens and viral antigens. ${ }^{3}$ If the major external antigen of some virus has the same specificity as a given HLA antigen, then those who carry this particular antigen may not be able to develop an immune response and thus may be more susceptible to infection by it. Although speculative, this hypothesis may help to explain how immune response genes may be components in the pathogenesis of some diseases associated with particular races.

\footnotetext{
${ }^{1}$ Behrman S. African race-influenced bilateral amblyopia among Wes Indian immigrants in the United Kingdom. Br F Ophthalmol 1962;46 554-8.

${ }^{2}$ Fasler JJ, Rose FC. West Indian amblyopia. Postgrad Med $\mathcal{f} 1980 ; 56$ 494-500.

${ }^{3}$ Svejgaard A, Platz P, Ryder LP, Nielsen LS, Thomsen M. HL-A and disease associations. Transplantation Reviews 1975;22:3-43.
}

\section{Endocrine function and immunity}

The association between endocrine function and immunity has been recognised only recently, but an effect of hormones on lymphoid tissue has in fact been documented for at least 60 years. ${ }^{1}$ Much of this work has been carried out in animals and has concentrated mostly on adrenocortical hormones. Adrenalectomy has been found to cause an absolute increase in the gross weight of lymphoid tissue in almost every species of animal, ${ }^{2}$ while the administration of adrenocortical hormones causes lymphatic involution. ${ }^{3}$ Similar stimulatory effects have been reported after orchidectomy ${ }^{2} 45$ and oophorectomy, ${ }^{2}$ and, as with the adrenals, treatment with the hormones concerned leads to involution of lymphoid tissue. ${ }^{6}$

These two examples, from the vast amount of research on the relation between hormones and lymphoid tissues, are evidence of a basic (though not absolute) principle: if an endocrine system is reversed-for example, by adrenalectomy -lymphoid tissue increases in weight; if the same system is potentiated by giving exogenous hormones the lymphoid response is involution.

Yet despite these observations little research has been carried out on the effects of hormones on peripheral lymphatic effects-a natural extension of the earlier work. Nevertheless, lymphocytosis has been reported in animals after adrenalectomy $^{7}$ and in patients with Addison's disease ${ }^{8}$; while animals given adrenocortical hormones have reduced lymphocyte counts in the peripheral blood, ${ }^{7}$ as have patients with Cushing's disease. ${ }^{9}$ Similarly, experiments on prepubertal and postpubertal mice treated with sex hormones ${ }^{10}$ have shown that giving androgen to males and oestrogen to females reduces the lymphocyte count. Sex hormone reversal in females produced by giving them androgens results in a lymphocytosis, but no comparable observation has been made in male mice receiving oestrogen.

These effects of hormones on lymphoid tissue and on peripheral blood lymphocytes in animals can be better 
appreciated in the light of the classical experiments of Medawar and his colleagues, ${ }^{11}$ who showed that cell-mediated immunity could be depressed by cortisone. A similar depression of cell-mediated immunity has been reported in male and female mice receiving androgen and oestrogen respectively. ${ }^{10}$ In contrast, after orchidectomy in mice cell-mediated immunity - as measured by skin graft rejection ${ }^{12}$ and protection against tumour induction ${ }^{5}$-is stimulated; while tumour growth can be inhibited in male mice given oestrogen and females given androgen. ${ }^{10}$ These and other studies provide strong evidence for a correlation between the effects of hormones on gross lymphoid tissue, peripheral lymphocyte count, and cell-mediated immunity.

The clinical implications of this experimental work, particularly in the treatment of cancer, are still being studied; but patients with advanced breast cancer who have responded to hormone treatment have already been found to show stimulation of cell-mediated immunity. ${ }^{13} 14$ The immunological response to sex hormones has been extensively investigated in patients with prostatic cancer. ${ }^{15-17}$ There is mounting evidence that the blanket use of oestrogens may inhibit some of the more desirable immunological effects, particularly the development of prostate-specific antibodies ${ }^{1819}$; and that the patient's hormonal status should be carefully and critically assessed before treatment is started. Such an assessment may well suggest an alternative treatment strategy.

The endocrine-immunological pathway may possibly be one of several mechanisms in the process of tumour regression. Clinical findings, at all events, appear to be compatible with the results of experiments in animals. ${ }^{20}$ The mounting evidence that interaction between hormones and immune processes is of clinical importance should not be ignored.

${ }^{1}$ Hammar JA. The new views as to the morphology of the thymus gland and their bearing on the problem of the function of the thymus. Endocrinology $1921 ; 5: 543-73$.

${ }^{2}$ Rapela CE. Influencia de la extirpacion suprarrenal sobre el timo. Revista de la Sociedad Argentina de Biologia 1944;20:423-39.

${ }^{3}$ Selye $\mathrm{H}$. Thymus and adrenals in response of organism to injuries and intoxifications. Br $\mathcal{F}$ Exp Pathol 1936;17:234-48.

4 Castro JE. Androgen deprivation as a stimulant of immunity. In : Braun W, Ungar J, eds. Non-specific factors influencing host resistance. A reexamination. Basle: Karger, 1973:277-84.

${ }^{5}$ Castro JE. Protective effects of orchidectomy on tumour induction and transplantation in mice. Br $\mathcal{F}$ Surg 1972;59:904

${ }^{6}$ Selye H, Albert S. Morphogenetic actions of various steroids in castrate male rat. F Pharmacol Exp Ther $1942 ; 76: 137-48$.

${ }^{7}$ Dougherty TF, White A. Functional alterations in lymphoid tissue induced by adrenal cortical secretion. Am 7 Anat 1945;77:81-116.

${ }^{8}$ Báez-Villaseñor J, Rath CE, Finch CA. The blood picture in Addison's disease. Blood 1948;3:769-73.

${ }^{9}$ De La Balze FA, Reifenstein EC, Albright F. Differential blood counts in certain adrenal cortical disorders (Cushing's syndrome, Addison's disease and pan hypopituitarism). F Clin Endocrinol Metab 1946;6:312-9.

10 Franks CR, Perkins FT, Bishop D. The effect of sex hormones on the growth of HeLa tumour modules in male and female mice. $\mathrm{Br} \mathcal{F}$ Cancer $1975 ; 31: 100-10$.

1 Billingham RE, Krohn PL, Medawar PB. Effect of cortisone on survival of skin homografts in rabbits. Br Med f $1951 ; \mathrm{i}: 1157-63$.

12 Castro JE, Hamilton DNH. Adrenalectomy and orchidectomy as immunopotentiating procedures. Transplantation 1972;13:614-6.

${ }^{13}$ Franks CR, Williams Y. The effect of sex hormones on peripheral immunity in patients with advanced breast cancer. Clin Oncol 1978;4: 19-24.

14 Franks CR, Williams Y. Prognostic value of peripheral lymphocyte count in hormone therapy of advanced breast cancer. $\mathrm{Br} \mathcal{F}$ Cancer $1976 ; 34: 641-4$.

${ }^{15}$ Ablin RJ. Immunobiology of the prostate. In: Tannenbaum M, ed. Urological pathology-the prostate. Philadelphia: Lee and Febiger, 1977:33-98.

16 Ablin RJ, Bhatti RA, Guinan PD. Effect of oestrogen on tumor-associated immunity in patients with adenocarcinoma of the prostate. Cancer Res 1978;38:3702-6.

17 Sljivic VS, Warr GW. Oestrogens and immunity. Periodicum Biologorium $1973 ; 75: 231-44$

${ }^{18}$ Stoll HW, Ansell JS, Barnes MS, Barnes GW. The autoimmune response to male reproductive tissues of rabbits. III : Effects of testosterone and oestrogen on cryoimmunogenic and immunochemical expressions of the central accessory glands. Invest Urol 1974;12:236-45.

${ }^{19}$ Ablin RJ, Barnes GW, Stoll HW. Cryostimulation. Androgenic and ontogenic dependence of the immune response following in situ autosensitisation. Cryobiology 1975;12:571.

${ }^{20}$ Franks CR. Endocrine function and the immune process. In: Stoll B, ed. Hormonal management of endocrine related cancer. London: Lloyd-Luke $1981: 187-93$.

\section{Non-ulcer uses of cimetidine}

A recent international symposium in London on cimetidine not only discussed its well-known uses in peptic ulcer and oesophagitis but also explored the value of $\mathrm{H}_{2}$-blockers in other conditions, such as pancreatitis and gastrointestinal haemorrhage.

In patients with malabsorption from pancreatic insufficiency (whether from pancreatitis or from resection) supplements of pancreatic enzyme often fail to reduce steatorrhoea because the enzymes are either irreversibly inactivated by acid in the stomach or have their activity reduced by an acidic $\mathrm{pH}$ in the duodenum, especially if there is gastric hypersecretion due to the pancreatic disease. An additional deleterious effect of a low $\mathrm{pH}$ is the precipitation of bile acids and their binding to dietary protein.

Enteric coating has not been successful in protecting enzyme supplements, ${ }^{1}$ but antacids with each meal are useful. ${ }^{2}{ }^{3}$ When cimetidine is given before each meal with the enzymes the problem is greatly simplified. Steatorrhoea is reduced, ${ }^{14}$ often with an increase in weight and wellbeing. ${ }^{5}$ Steatorrhoea and diarrhoea after ileal resection may also be improved by cimetidine. ${ }^{6}$

Cimetidine probably has little direct or indirect effect on the output of enzymes in response to food. It might reduce output of pancreatic bicarbonate, which is stimulated by the acid and mediated by secretin; and it has therefore been tried in acute pancreatitis, in which one longstanding treatment (though it is not supported by any evidence from controlled trials ${ }^{7-9}$ ) is nasogastric suction to decrease the gastric acid reaching the duodenum. Unfortunately careful, controlled, and doubleblind trials, with randomised patients, have shown that not only is cimetidine not superior to placebo in mild to moderate alcoholic pancreatitis ${ }^{10}$ but that it may actually increase and prolong hyperamylasaemia. This effect is probably not a harmless change in amylase excretion but a direct toxic action on the pancreas, as has been seen in studies in animals ${ }^{11} 12$ and, rarely, in patients with duodenal ulcer. ${ }^{13} 14$

At the symposium Bommelaer gave a preliminary analysis of a multicentre trial in France of cimetidine $1.6 \mathrm{~g} / 24 \mathrm{~h}$ for an average of three weeks, given firstly as an intravenous infusion and then by mouth, in acute pancreatitis. Both the incidence of complications and the activity of serum amylase were higher in the 15 patients treated with cimetidine (of whom four died) than in the 17 patients (none of whom died) given placebo. Cimetidine should not, then, be prescribed for acute pancreatitis; it may be a valuable adjunct to pancreatic enzyme replacement treatment in pancreatic insufficiency; and it has not been tested in chronic relapsing pancreatitis.

Is cimetidine useful for preventing stress-induced upper gastrointestinal haemorrhage, and is any type of alimentary bleeding stopped by cimetidine or prevented from recurring ? The mechanisms of stress-erosive gastroduodenitis are obscure; but acid is usually implicated, at least potentially, and treatment with antacids has long been recommended as a 